\title{
In silico Screening of Some Compounds Derived from the Desert Medicinal Plant Rhazya stricta for Potential Treatment of COVID -19
}

\author{
Nabih A. Baeshen
}

King Abdulaziz University

Abdulaziz 0. Albeshri

King Abdulaziz University

Naseebh N. Baeshen

University of Jeddah

Roba Attar

University of Jeddah

Alaa Karkashan

University of Jeddah

\section{Basma Abbas}

University of Jeddah

Thamer A. Bouback

King Abdulaziz University

Abdullah A. Aljaddawi

King Abdulaziz University

Mohammed Y. Refai

University of Jeddah

Hayam S. Abdelkader

University of Jeddah

Abdullah Al Tamim

Saudi Food \& Drug Authority (SFDA)

Abdullah Alowaifeer

Saudi Food \& Drug Authority (SFDA)

Mohammed N. Baeshen ( $\square$ mnbaeshen@uj.edu.sa )

University of Jeddah

\section{Research Article}

Keywords: SARS-CoV-2, molecular docking, Rhazya Stricta, MD simulations, RMSD, RMSF. 
Posted Date: July 22nd, 2021

DOl: https://doi.org/10.21203/rs.3.rs-653724/v1

License: (c) (i) This work is licensed under a Creative Commons Attribution 4.0 International License. Read Full License 


\section{Abstract}

The recent emerging SARS-CoV-2 pandemic which was identified as COVID-19 disease has become a global health concern. It resulted in a major pneumonia outbreak worldwide. Currently, there are no approved drugs and several attempts have been made to use computational program approaches in drug repurposing for COVID-19 treatment. The SARS-CoV-2 spike glycoprotein receptor-binding domain (RBD) is vital for binding to the hACE2 receptor, which initiates entry into human cells, and thus is a key target for antiviral compound development. Many herbal natural products have been proved to exert virucidal activity against the vast majority of pathogenic viruses. Rhazya stricta, a folkloric medicinal desert plant of Saudi Arabia was shown to exhibit bactericidal activity against a verity of pathogens including Methicillin-resistant Staphylococcus aureus (MRSA) and some other Multidrug-Resistant Organisms (MDR's). This study aims to test for antiviral activity of the folkloric medicinal desert plant Rhazya stricta against coronavirus SARS-CoV-2. We identified three non-alkaloid herbal natural compounds Lig230, Lig434, and Lig68 from Rhazya Stricta that bind and interact significantly with RBD (PDB: I.D. 6M0J) by using virtual screening and computer aiding program Autodock vina. Based on the results of docking scores, molecular docking simulations, RMSD, RMSF, and radius of gyration (Rg), the virtually screened antiviral compounds showed good binding interactions and high stability. Lig230 revealed the highest average of interaction energy during MD simulation (- $417.284 \mathrm{~kJ} / \mathrm{mol})$ followed by Lig434 $(-366.186$ $\mathrm{kJ} / \mathrm{mol})$ and the lowest interaction energy was by Lig68 $(-352.5872 \mathrm{~kJ} / \mathrm{mol})$. To evaluate the oral bioavailability, a drug-likeness profile was performed by SwissADME and the results revealed that these compounds expected to confront permeability and solubility difficulties if they were introduced orally. In conclusion, the suggested three compounds can serve as potential anti- SARS-CoV-2 and should be furtherly tested in vitro and in vivo.

\section{Introduction}

In late December 2019, an outbreak of pneumonia was discovered in Wuhan, China, but the source of the outbreak was unknown ${ }^{1,2}$. The causative agent was a novel coronavirus termed as severe acute respiratory syndrome coronavirus 2 (SARS-CoV-2) ${ }^{2}$. WHO announced that SARS-CoV-2 is a global public health concern on January 30,2020. The new epidemic was formally designated as coronavirus disease 19 (COVID-19) ${ }^{1}$. SARS-CoV-2 is considered a novel beta-coronavirus that infects humans and may originate from bats ${ }^{3,4}$. It can be spread between people by direct contact, respiratory droplets, and aerosols and is not restricted to the respiratory tract ${ }^{5}$. The RNA genome of SARS-CoV is a positive sense ssRNA ( $29.9 \mathrm{kbp})$ that encodes four structural proteins and sixteen non-structural proteins. Host cell entry by coronavirus is facilitated by the spike glycoprotein $6,7,8$.

ACE2 is a transmembrane protein, which is the receptor for the SARS-CoV2 spike (S) glycoprotein particularly recognized by the RBD ${ }^{9,10}$. Therefore, the $S$ glycoprotein is considered an attractive target for molecular docking which is an efficient, rapid and cost-effective tool in drug discovery. It aids in an early and efficient prediction compared to the experimental studies trials. 
Over time, plant and microbial-derived substances have been used to treat many diseases. These phytochemical compounds can be studied using computational techniques for drug discovery, pharmacokinetics and pharmacodynamics ${ }^{11}$. Rhazya stricta is an important folkloric medicinal desert plant of Apocynaceae family. It is a local plant found around and along some valleys of the desert of Saudi Arabia. The plant was first described in the western region of Saudi Arabia by Batanouny and Baeshin in 1982 and $1983^{12,13}$. It is used to treat various diseases such as arthritis, skin diseases, stomach diseases and diabetes; and even cancer ${ }^{14,15}$. Previous studies have shown interesting results for the evaluation of the alkaloid extracts of $R$. stricta against numerous diseases. Our previous studies showed the antibacterial activities of non-alkaloid extracts derived from $R$. stricta leaves against multidrug-resistant (MDR) and extended-spectrum beta-lactamases (ESBLs) bacteria, which indicated a potential therapeutic against several Gram-positive and Gram-negative pathogens ${ }^{16,17}$. The non-alkaloid phytochemical compounds containing heterocyclic moieties extracted from $R$. stricta make it a potential drug candidate. A few non-alkaloidal constituents such as flavonoids ${ }^{18,19}$, glycosides ${ }^{16}$, terpenoids ${ }^{21}$, shikimate aromatics ${ }^{22}$ and fatty acid esters ${ }^{18,21}$ have also been isolated from $R$. stricta. The pyrrole ring structure has been found in some biologically active compounds other than alkaloids and possesses a range of antibacterial and therapeutic activities ${ }^{16,17}$. This pyrrole ring system can be found in amino acids, hydroxyproline, and other naturally occurring compounds. Some of the pyrrole compounds are currently on the market and others are in clinical research.

Since the onset of the epidemic of SARS-CoV-2, novel drug discovery research has increased. Considering the time, computational approaches are considered the most efficient method for drug discovery ${ }^{21}$. The present study aims to virtually screen the non-alkaloid phytochemical compounds isolated from $R$. Stricta plant using computational methods for the development of drug candidates for the treatment of COVID 19.

\section{Materials And Methods}

Collection and preparation of plant Samples. Rhazya stricta plant was collected from its natural habitat in the desert in Al Gholah region near Asfan road $(21.9684537,39.2675785)$ - Jeddah province on Sunday, June 7, 2020. The temperature was $38^{\circ} \mathrm{C}$ at $11: 18$ am (Fig. 1). The voucher specimen was deposited in the Department of Biological Sciences Herbarium at King Abdulaziz University (Number $1150 / M / 75$ collected by N. Baeshen, M. Baeshen and J. Sabir). The plant material was taken to the laboratory and the leaves were cut and washed with running water to remove the dust and left to dry in the laboratory at room temperature. A week later, the dry leaves were ground into fine powder for further steps of extraction and biochemical analysis. The Authors confirm that the the experiments on the plants of the present study complies with international and national guidelines.

Alkaloids and non-alkaloids were extracted from Rhazya stricta plant as described by Khan et al., (2016) 14. In brief, ten gm of plant material was weighed into a clean volumetric flask and $20 \mathrm{ml}$ of absolute ethanol $(99 \%)$ was added. The mixture was allowed to sit in the fridge $\left(4^{\circ} \mathrm{C}\right)$ for two days. Ethanol was 
removed by placing the mixture over Whatman filter paper (0.45um) and drying the plant material with nitrogen gas. After that, an allocate of $5 \mathrm{gm}$ of plant material was transferred into a clean volumetric flask and $40 \mathrm{ml}$ of $1 \mathrm{~mol} / \mathrm{L} \mathrm{HCL}$ and $40 \mathrm{ml}$ of HPLC grade chloroform was added. The chloroform layer was collected and filtered through a PTFE disk filter, then transferred into an LC vial for analysis of nonalkaloids. As for alkaloids, sodium hydroxide was added to the plant mixture to adjust the pH then $40 \mathrm{ml}$ of HPLC grade chloroform was added. The chloroform layer which contains alkaloids was filtered through a PTFE disk filter and transferred into a liquid chromatography vial for analysis.

LC-MS analysis and data processing. The study was performed using an LC-M system that included an ACQUITY UPLC I-Class (Waters Technologies, USA) coupled with a 6500 Qtrap (AB Sciex, Canada). Chromatographic separation was performed using a Zorbax XDB C18 column (2.1 X $150 \mathrm{~mm} .3 .5 \mu \mathrm{m})$ and held at $40^{\circ} \mathrm{C}$ with a flow rate of $300 \mu \mathrm{L} / \mathrm{min}$ and an injection volume of $10 \mu \mathrm{L}$. A $(0.1 \%$ formic acid in HPLC grade water) and $B(0.1 \%$ formic acid in HPLC grade acetonitrile) were used as the mobile phase. The linear elution gradient was as follows: $2 \%$ B (from 0 to 2), 95\% B (from 2 to 24 ), $95 \%$ B (held for 2 $\mathrm{min})$, then 4 min equilibration time. The data from electrospray ionization mass spectroscopy (ESI-MS) were collected in positive mode (ES +) with an electrode voltage of $5500 \mathrm{~V}$, a declustering potential (DP) of $90 \mathrm{~V}$, collision energy of $30 \mathrm{~V}$, and an input potential of $10 \mathrm{~V}$. Nitrogen was used as a nebulizer gas and as a curtain gas at $30 \mathrm{psi}$. Mass spectra were acquired in a mass range of $100-900 \mathrm{~m} / \mathrm{z}$, and a scan rate of 1000 was used to search for enhanced production. Upon completion of the analysis, the LC-MS data files were downloaded in wiff format and then translated to MZxml using MSConvert (ProteoWizard 3.0.20270). Mzmine (version 2.53) software was used to analyze the results (https://github.com/mzmine/mzmine2/releases/tag/v2.53) ${ }^{22}$. Following data import into MZmine, a minimum intensity cutoff of 1,000 was used and the retention time was set to a tolerance of 0.2 min. Then, the modified peaks were compiled into a single mass list to enable detection and comparison.

Ligands and protein preparation. A total of 573 Non-alkaloid compounds found naturally in Rhazya Stricta were obtained from LC/MS and HPLC analysis. Chemical structures of the compounds obtained from the PubChem database (https://pubchem.ncbi.nlm.nih.gov/) ${ }^{23}$ as 3D SDF files or the Online Smile translator (https://cactus.nci.nih.gov/gifcreator/) ${ }^{24}$ into PDB files (https://www.rcsb.org/) ${ }^{25}$. Receptor binding domains (RBD) which locate (333-526 aa) in the SARS-CoV-2 spike protein (PDB: I.D. 6MOJ) ${ }^{26}$ was used as a possible target to test the potential activity of the compounds as virus entry inhibitor.

Virtual screening. By using ADT Molecular viewer ${ }^{27}$, non-polar hydrogen atoms were merged and Kollman charges were added to the RBD. The compute Gasteiger charge was added and all the rotatable bonds were kept rotatable and the root of the ligands was detected. The grid box was concentrated on the active site interface which contains the involving residues in connection with hACE2 receptor (K417, G446, Y449, Y453, L455, F456, A475, F486, N487, Y489, Q493, G496, Q498, T500, N501, G502, Y505). Autodock vina ${ }^{28}$ was used to investigate the antiviral activity of the ligands. To visualize the positions of the 3D ligands PyMol was used and LigPlot ${ }^{+}$to represent it as plotting ${ }^{29,30}$. 
Drug-likeness analysis. The lowest binding affinity of the compounds in Molecular docking results was submitted to SwissADME webserver ${ }^{31}$ to predicate the Drug-likeness profile, by applying Lipinski's rule of five, which takes into account the molecular weight, lipophilicity, number of hydrogen bond donors, and number of hydrogen bond acceptors ${ }^{32}$.

Molecular dynamic simulation. The molecular dynamic simulation was performed for $100 \mathrm{~ns}$ timescale using Gromacs $2020.3(12)^{33}$. The RBD-ligand complexes of the top three compounds as obtaine $30^{34}$ and the ligands topology was generated using CgenF web-server ${ }^{35}$. After solvating the dodecahedral box with the TIP3P water model and neutralizing it with two CL-, the system's energy was reduced using the steepest descent algorithm, and the system's long-range electrostatic interactions were measured using the Particle-Mesh Ewald equation. Under periodic boundary conditions, the long-range electrostatic and long-range Van der Waals cut-offs are set to $1.2 \mathrm{~nm}$. To stabilize the system thermodynamically NVT and NPT Equilibration were conducted for 100 ps, and the ligands are restrained to the RBD under 300K reference temperature and 1 bar reference pressure. Finally, root mean square deviation (RMSD), root mean square fluctuation (RMSF), and trajectories at the termination point (100 ns) analyzed using the graph plotting tool Xmgrace ${ }^{36}$.

\section{Results And Discussion}

HPLC analysis. The non-alkaloids of $R$. stricta were isolated using the HPLC method. Separation using the HPLC method confirmed the existence of nine non-alkaloid compounds (Table 1) and seven additional alkaloids as minor components.

Molecular Docking. Autodock vina was used to estimate the binding affinity and compounds possess into the binding site cavity of the RBD I.D. 6MOJ (Fig. 2). Among all the compounds, compounds with a $0.8 \mathrm{kcal}$ binding affinity were chosen. Lig 434 showed the least binding affinity, and its atoms involved in interaction with RBD protein by six hydrogen bonds, and the binding affinity was $-8.5 \mathrm{kcal} / \mathrm{mol}$ (Fig. 2A). Also, several electrostatic contacts involved. Lig 68 showed the same binding affinity $-8.5 \mathrm{cal} / \mathrm{mol}$ and bounded to RBD protein with four hydrogen bonds (Fig. 2B). Lig230 with $-8.5 \mathrm{kcal} / \mathrm{mol}$ and its position enabled to form only two hydrogen bonds (Fig. 2C). These compounds had remarkable molecular docking results, which make them good candidates to perform MD simulations. The other compounds revealed a close result and potential activity, but we confined the MD simulation only to the top three compounds.

\section{Molecular Dynamic Simulation.}

To validate the molecular docking results, molecular dynamic simulation, root mean square deviation (RMSD), root mean square fluctuation (RMSF), and radius of gyration ( $\mathrm{Rg}$ ) were performed. The RBD ligand complexes results represented by Xmgrace graph plotting. From the start steps up to last, Lig434 is poorly stable during MD simulation. And its RMSD value reached $0.5 \mathrm{~nm}$ in some steps. In addition, 
Lig434 terminated the MD simulation with $0.34 \mathrm{~nm}$. Lig68 stabilized after $80 \mathrm{~ns}$ with RMSD $0.28 \mathrm{~nm}$. Finally, Lig230 elucidated high stabilization with RMSD 0.2 nm (Fig. 3A).

RMSF plotting graph showed a fluctuation and flexible residues of the RBD as a function of time (Fig. 3B). Eleven residues were showed with respectively high fluctuations, $(333,369,417,505,511$, and 519) related to RBD-Lig230 complexes, $(333,324,444,449$, and 466) related to RBD-lig434 complex and (449) related to RBD-Lig 68 complex. All these residues showed vibration during MD simulation (Fig. 3C).

The radius of gyration $(\mathrm{Rg})$ measures the compactness and folding of the RBD protein. The results of RBD-complexes were approximately matching the Rg of RBD alone which means the protein properly folded and compacted during the MD simulation.

Hydrogen bonds are an important indicator of intermolecular interaction between the RBD and the ligands compounds. Lig434 has a high tendency in the formation of highly variable hydrogen bonds and predicated to form 1-3 hydrogen bonds and a maximum of five hydrogen bonds was formed. Lig68 results showed 2-4 hydrogen formed during MD simulation and a maximum of five hydrogen bonds was observed, which is equal to the number of hydrogen bonds in the molecular docking results. In the case of Lig230, 1-3 hydrogen bonds and a maximum of three hydrogen bonds were formed. Until the end of 100 ns, Lig68 and Lig230 are still connected to RBD by 3 and 2 hydrogen bonds (Fig. 3D). The binding, stability, and strength of the interaction were analyzed by extracting the Lennard-Jones (LJ) and Coulomb (Coul) energies. Lig230 revealed the highest average of interaction energy during MD simulation $(-417.284 \mathrm{~kJ} / \mathrm{mol})$ followed by Lig434 $(-366.186 \mathrm{~kJ} / \mathrm{mol})$ and the lowest interaction energy was by Lig68 (- $352.5872 \mathrm{~kJ} / \mathrm{mol})$ (Table 2).

Binding pose of non-alkaloid compounds during MD Simulation. The MD simulation analysis was performed to determine the stability of the nonalkaloid compounds docked to the hACE2 receptor calculated from the molecular docking simulations. The virtually studied non-alkaloid compounds (Lig 434, Lig 68, and Lig 230) docked to the SARS-CoV-2 ACE2 receptor were screened for complex stability and formation of a satisfactory position of the ligand molecules through intermolecular interactions to achieve a global energy minimum during the simulation time (100 ns). The last trajectory (100 ns point) of the Protein-Ligands complexes was extracted to evaluate and visualize the deviation that occurred to the ligand's positions. The position variation and intermolecular contact were proportionally related to each other, where the increased position variation was confronted with an increase in intermolecular contact. Comparing to the Molecular docking poses (initial configuration), all the ligands preserved their poses in the binding cavity which contains the critical residues in the RBD-hACE2 interaction process. The RMSD of the ligands in the 100 ns trajectory (Lig230: $0.20 \mathrm{~A}^{\circ}$, Lig68: $0.28 \mathrm{~A}^{\circ}$ and Lig434: $0.34 \mathrm{~A}^{\circ}$ ) indicates that the Lig230 faced the slightest conformational changes (Fig. 4).

Drug-likeness. To evaluate the oral bioavailability of these compounds, a drug-likeness analysis is done by applying the five rules of the Lipinski method. All the compounds had two violations, which basically found in the Molecular Weight and the number of $\mathrm{N}$ and $\mathrm{O}$ atoms (Table 3). These results suggest, the three compounds expected to confront permeability and solubility difficulties if they introduce by the oral 
route, which adds another route of exposure into consideration (inhalation, injection, transdermal route, etc).

The assessment of absorption, distribution, metabolism and excretion (ADME) have been performed for the top leading compounds (Lig 68, Lig 434 and Lig 230) using SwissADME web tool. Bioavailability Radar is shown (Fig. 5) to provide a quick assessment of drug-likeness.

Six physicochemical characteristics are taken into consideration: lipophilicity, size, polarity, solubility, flexibility and saturation. On each axis, a physicochemical range was specified using descriptors adapted from ${ }^{37}$ and ${ }^{38}$ and represented as a pink region within which the molecule's radar plot must completely lie to be considered drug-like. The results revealed that the Lig 68 and Lig 434 were not orally bioavailable, because too flexible and too polar. It can be concluded that the compound (Lig 230) has a good water solubility, which is necessary for oral bioavailability and absorption, as well as a good lipophilicity.

\section{Conclusion}

The lead compounds Lig230 and Lig68 exhibited remarkable potency and showed strong interaction with RBD amino acid residues of the SARS-CoV-2 spike protein. Virtually screened non-alkaloid compounds identified in this study may inhibit viral binding to host cells. In addition, clinical and/or experimental trials may help to open the discovery of new antiviral drugs against SARS-CoV-2, and it is recommended that these compounds be tested in in vitro and in vivo.

\section{Declarations}

Acknowledgement. This project was funded by the Deanship of Scientific Research (DSR) at King Abdulaziz University, Jeddah, under grant no. GCV19-29-1441. The authors, therefore, acknowledge with thanks DSR for technical support.

Author conttributions statements. N.A.B., N.N.B., A.A.J. and M.N.B. designed and wrote the project, A.O.A. conducted In Silico and MD stimulation analysis, M.N.B, T.A.B, R.A, A.K. and B.A. collected the plant material and achieved plant experiments, H.S.A. wrote the manuscript. All authors reviewed the manuscript.

Conflict of interest. Authors declare no conflicts of interest or ethical problems.

\section{References}

1. Sun, L., Sun, Z., Wu, L., Zhu, Z., Zhang, F., Shang, Z., Jia, Y., Gu, J., Zhou, Y., Wang, Y., Liu, N., \& Liu, W. (2021). Prevalence and risk factors for acute posttraumatic stress disorder during the COVID-19 outbreak. Journal of Affective Disorders, 283, 123-129. 
2. Zhu, N., Zhang, D., Wang, W., Li, X., Yang, B., Song, J., Zhao, X., Huang, B., Shi, W., Lu, R., Niu, P., Zhan, F., Ma, X., Wang, D., Xu, W., Wu, G., Gao, G. F., Tan, W., \& China Novel Coronavirus Investigating and Research Team (2020). A Novel Coronavirus from Patients with Pneumonia in China, 2019. New England Journalof Medicine, 382(8):727-733.

3. Zhou, P., Yang, X. L., Wang, X. G., Hu, B., Zhang, L., Zhang, W., ... \& Shi, Z. L. (2020). A pneumonia outbreak associated with a new coronavirus of probable bat origin. Nature, 579(7798), 270-273.

4. Zhang, R., Li, Y., Zhang, A. L., Wang, Y., \& Molina, M. J. (2020). Identifying airborne transmission as the dominant route for the spread of COVID-19. Proceedings of the National Academy of Sciences, 117(26), 14857-14863.

5. Han, Y., Du, J., Su, H., Zhang, J., Zhu, G., Zhang, S., ... \& Jin, Q. (2019). Identification of Diverse Bat Alphacoronaviruses and Betacoronaviruses in China Provides New Insights Into the Evolution and Origin of Coronavirus-Related Diseases. Frontiers in Microbiology, 10, 1900.

6. Han, Y., Du, J., Su, H., Zhang, J., Zhu, G., Zhang, S., ... \& Jin, Q. (2020). Corrigendum: Identification of Diverse Bat Alphacoronaviruses and Betacoronaviruses in China Provides New Insights Into the Evolution and Origin of Coronavirus-Related Diseases. Frontiers in Microbiology, 11.

7. Li, W., Moore, M. J., Vasilieva, N., Sui, J., Wong, S. K., Berne, M. A., ... \& Farzan, M. (2003). Angiotensinconverting enzyme 2 is a functional receptor for the SARS coronavirus. Nature, 426(6965), 450-454.

8. Li, F. (2016). Structure, function, and evolution of coronavirus spike proteins. Annual review of virology, 3, 237-261.

9. Li, F., Li, W., Farzan, M., \& Harrison, S. C. (2005). Structure of SARS coronavirus spike receptor-binding domain complexed with receptor. Science, 309(5742), 1864-1868.

10. Walls, A. C., Park, Y. J., Tortorici, M. A., Wall, A., McGuire, A. T., \& Veesler, D. (2020). Structure, function, and antigenicity of the SARS-CoV-2 spike glycoprotein. Cell, 181(2), 281-292.

11. Batanouny H., Baeshin N. A. (1982). Studies on the flora od Saudi Arabia II. The Madina-Badr road Saudi Arabia. Bull. Fac. Sci., K.A.U., Jeddah, 6, 1-26.

12. Batanouny H., Baeshin N. A. (1983). Plant communities along the Medina-Badr Road across the Hejaz mountains, Saudi Arabia. Vegetatio, 53, 33-43.

13. Thomford, N. E., Senthebane, D. A., Rowe, A., Munro, D., Seele, P., Maroyi, A., \& Dzobo, K. (2018). Natural products for drug discovery in the 21 st century: Innovations for novel drug discovery. International journal of molecular sciences, 19(6), 1578.

14. Baeshen, N., Lari, S., Al Doghaither, H. A., \& Ramadan, H. A. (2010). Effect of Rhazya stricta extract on rat adiponectin gene and insulin resistance. Journal of American Science, 6(12), 1237-1245.

15. Baeshen, N. A., Elkady, A. I., Abuzinadah, O. A., \& Mutwakil, M. H. (2012). Potential anticancer activity of the medicinal herb, Rhazya stricta, against human breast cancer. African Journal of Biotechnology, 11(37), 8960-8972.

16. Khan, R., Baeshen, M. N., Saini, K. S., Bora, R. S., Al-Hejin, A. M., \& Baeshen, N. A. (2016). Antibacterial activities of Rhazya stricta leaf extracts against multidrug-resistant human pathogens. 
Biotechnology \& Biotechnological Equipment, 30(5), 1016-1025.

17. Khan, R., Baeshen, M. N., Saini, K. S., Bora, R. S., Al-Hejin, A. M., El-Hamidy, S. M., \& Baeshen, N. A. (2016). Antibacterial activity of Rhazya stricta non-alkaloid extract against methicillin-resistant Staphylococcus aureus. Biological System Open Access, 5(157), 2.

18. Zaman, K. (1987). Studies on the Chemical Constituents of Roots of Rhazya Stricta Decaisne (Doctoral dissertation, UNIVERSITY OF KARACHI, KARACHI).

19. Sultana, N., Choudhary, M. I., Ali, S., Anjum, S., \& Fun, H. K. (2005). 5, 7-Dihydroxy-6, 2'dimethoxyisoflavone. Acta Crystallographica Section E: Structure Reports Online, 61(6), o181201814.

20. Andersen, W. K., Omar, A. A., \& Christensen, S. B. (1986). Isorhamnetin3-(2, 6dirhamnosylgalactoside)-7-rhamnoside and 3-(6-rhamnosylgalactoside)-7-rhamnoside from Rhazya stricta. Phytochemistry, 26(1), 291-294.

21. Sultana, N., \& Khalid, A. (2010). Phytochemical and enzyme inhibitory studies on indigenous medicinal plant Rhazya stricta. Natural product research, 24(4), 305-314.

22. Abdel Mogib, S. A., Basif, S. A., \& Ezmirly, S. T. (1998). Aspidospermidine and dehydroAsppidospermidine from Rhazya stricta. Saudi Chem. Soc, 2, 141.

23. Mohamed, K., Yazdanpanah, N., Saghazadeh, A., \& Rezaei, N. (2021). Computational drug discovery and repurposing for the treatment of COVID-19: a systematic review. Bioorganic chemistry, 106, 104490.

24. ttps://github.com/mzmine/mzmine2/releases/tag/v2.53

25. https://pubchem.ncbi.nlm.nih.gov/

26. http://cactus.nci.nih.gov/gifcreator/

27. https://www.rcsb.org/

28. Lan, J., Ge, J., Yu, J., Shan, S., Zhou, H., Fan, S., ... \& Wang, X. (2020). Structure of the SARS-CoV-2 spike receptor-binding domain bound to the ACE2 receptor. Nature, 581(7807), 215-220.

29. Sanner, M. F. (1999). Python: a programming language for software integration and development. J Mol Graph Model, 17(1), 57-61.

30. Trott, O., \& Olson, A. J. (2010). AutoDock Vina: improving the speed and accuracy of docking with a new scoring function, efficient optimization, and multithreading. Journal of computational chemistry, 31(2), 455-461.

31. The PyMOL Molecular Graphics System, Version 2.0 Schrödinger, LLC.

32. Laskowski RA and Swindells MB (2011). LigPlot+: multiple ligand-protein interaction diagrams for drug discovery. Journal of Chemical Information and Modeling. 51 (10):2778-2786.

33. Lipinski, C. A., Lombardo, F., Dominy, B. W., \& Feeney, P. J. (1997). Experimental and computational approaches to estimate solubility and permeability in drug discovery and development settings. Advanced drug delivery reviews, 23(1-3), 3-25. 
34. Daina, A., Michielin, O., \& Zoete, V. (2017). SwissADME: a free web tool to evaluate pharmacokinetics, drug-likeness and medicinal chemistry friendliness of small molecules. Scientific reports, 7(1), 1-13.

35. Lemkul, J. (2019). From proteins to perturbed Hamiltonians: A suite of tutorials for the GROMACS2018 molecular simulation package [article v1. 0]. Living Journal of Computational Molecular Science, 1(1), 5068.

36. Vanommeslaeghe, K., Hatcher, E., Acharya, C., Kundu, S., Zhong, S., Shim, J., ... \& Mackerell Jr, A. D. (2010). CHARMM general force field: A force field for drug-like molecules compatible with the CHARMM all-atom additive biological force fields. Journal of computational chemistry, 31(4), 671690.

37. https://cgenff.paramchem.org

38. Turner, P. J. (2005). XMGRACE, Version 5.1. 19. Center for Coastal and Land-Margin Research, Oregon Graduate Institute of Science and Technology, Beaverton, OR.

\section{Tables}

Table 1. Top-ranked non-alkaloid compounds isolated from $R$. stricta and screened against SARS-CoV-2 RBD with their respective structures, docking score, and chemical formulae. 


\begin{tabular}{|c|c|c|c|c|c|c|c|}
\hline Pubchem CID & Superclass & Class & Subclass & Direct Parent & \begin{tabular}{|l|} 
Alternative Parents \\
\end{tabular} & Structure & $\begin{array}{c}\text { Docking score } \\
(\mathrm{kcal} / \mathrm{mol})\end{array}$ \\
\hline $\begin{array}{c}\text { Lig434 } \\
\text { CID: } 11585544 \\
\mathrm{C}_{28} \mathrm{H}_{32} \mathrm{ClN}_{7} \mathrm{O}_{6} \mathrm{~S}_{2}\end{array}$ & Benzenoids & $\begin{array}{l}\text { Benzene and } \\
\text { substituted } \\
\text { derivatives }\end{array}$ & $\begin{array}{c}\text { Benzenesulfona } \\
\text { mides }\end{array}$ & Tosyl compounds & Pyrrolopyridines & & -8.5 \\
\hline $\begin{array}{c}\text { Lig68 } \\
\frac{\mathrm{CID}: 137148428}{\mathrm{C}_{23} \mathrm{H}_{14} \mathrm{Cl}_{3} \mathrm{FN}_{6} \mathrm{O}_{5} \mathrm{~S}_{2}}\end{array}$ & Benzenoids & $\begin{array}{l}\text { Benzene and } \\
\text { substituted } \\
\text { derivatives }\end{array}$ & $\begin{array}{c}\text { Benzenesulfona } \\
\text { mides }\end{array}$ & Tosyl compounds & Pyrrolopyridines & & -8.5 \\
\hline $\begin{array}{c}\text { Lig230 } \\
\text { CID:135501155 } \\
\mathrm{C}_{29} \mathrm{H}_{29} \mathrm{~N}_{7} \mathrm{O}_{4}\end{array}$ & \begin{tabular}{|c|} 
Organic acids \\
and \\
derivatives
\end{tabular} & $\begin{array}{l}\text { Carboxylic } \\
\text { acids and } \\
\text { derivatives }\end{array}$ & $\begin{array}{c}\text { Amino acids, } \\
\text { peptides, and } \\
\text { analogues }\end{array}$ & $\begin{array}{c}\text { Amino acids and } \\
\text { derivatives }\end{array}$ & Toluenes & & -8.5 \\
\hline $\begin{array}{c}\mathrm{Lig} 308 \\
\mathrm{CID:46229392} \\
\mathrm{C}_{29} \mathrm{H}_{36} \mathrm{~F}_{3} \mathrm{~N}_{3} \mathrm{O}_{7} \mathrm{~S}_{2}\end{array}$ & Benzenoids & $\begin{array}{l}\text { Benzene and } \\
\text { substituted } \\
\text { derivatives }\end{array}$ & $\begin{array}{c}\text { Benzenesulfona } \\
\text { mides }\end{array}$ & $\begin{array}{l}\text { Trifluoromethyl- } \\
\text { benzenes }\end{array}$ & $\mathrm{N}$-acylpiperidines & & -8.3 \\
\hline $\begin{array}{c}\text { Lig355 } \\
\text { CID:14160295 } \\
\mathrm{C}_{32} \mathrm{H}_{33} \mathrm{~N}_{5} \mathrm{O}_{7}\end{array}$ & $\left|\begin{array}{c}\text { Organic acids } \\
\text { and } \\
\text { derivatives }\end{array}\right|$ & $\begin{array}{l}\text { Carboxylic } \\
\text { acids and } \\
\text { derivatives }\end{array}$ & $\begin{array}{c}\text { Amino acids, } \\
\text { peptides, and } \\
\text { analogues }\end{array}$ & Oligopeptides & $\begin{array}{l}\text { "N-acyl-alpha } \\
\text { amino acids" }\end{array}$ & & -8.2 \\
\hline $\begin{array}{c}\text { Lig461 } \\
\mathrm{C}_{27}{ }^{\mathrm{CID}: 3282882} \mathrm{H}_{23} \mathrm{Cl}_{2} \mathrm{~N}_{7} \mathrm{O}_{6} \mathrm{~S}_{2}\end{array}$ & Benzenoids & $\begin{array}{l}\text { Benzene and } \\
\text { substituted } \\
\text { derivatives }\end{array}$ & Anilides & $\begin{array}{c}\text { Benzenesulfonami } \\
\text { des }\end{array}$ & \begin{tabular}{|c|}
$\mathrm{N}-$ \\
acetylarylamines
\end{tabular} & & -8.2 \\
\hline $\begin{array}{c}\text { Lig363 } \\
\frac{\mathrm{CID}: 1677463}{\mathrm{C}_{29} \mathrm{H}_{18} \mathrm{Cl}_{3} \mathrm{~N}_{3} \mathrm{O}_{4}}\end{array}$ & Benzenoids & $\begin{array}{l}\text { Benzene and } \\
\text { substituted } \\
\text { derivatives }\end{array}$ & Anilides & Benzanilides & Diarylethers & & -8.1 \\
\hline $\begin{array}{c}\mathrm{Lig} 75 \\
\mathrm{CID}: 69307254 \\
\mathrm{C}_{30} \mathrm{H}_{38} \mathrm{~F}_{2} \mathrm{~N}_{6} \mathrm{O}_{9}\end{array}$ & $\begin{array}{c}\text { Organic acids } \\
\text { and } \\
\text { derivatives }\end{array}$ & $\begin{array}{c}\text { Peptidomimetic } \\
\mathrm{s}\end{array}$ & ic Depsipeptides & $\begin{array}{c}\text { Cyclic } \\
\text { depsipeptides }\end{array}$ & Macrolide lactams & & -8.0 \\
\hline $\begin{array}{c}\text { Lig152 } \\
\text { CID: } 60036944 \\
\mathrm{C}_{27} \mathrm{H}_{16} \mathrm{O}_{7}\end{array}$ & null & null & null & null & null & & -8.0 \\
\hline
\end{tabular}

Table 2. Binding energy, stability and strength of interaction of the lead compounds in complex with RBD $(6 \mathrm{MOJ})$ 


\begin{tabular}{|llll|}
\hline Compounds & $\begin{array}{l}\text { Coul-SR } \\
(\mathrm{kJ} / \mathrm{mol})\end{array}$ & $\begin{array}{l}\text { LJ-SR } \\
(\mathrm{kJ} / \mathrm{mol})\end{array}$ & $\begin{array}{l}\text { Total Energy } \\
(\mathrm{kJ} / \mathrm{mol})\end{array}$ \\
\hline Lig434 & -215.503 & -150.683 & -366.186 \\
\hline Lig68 & -261.979 & -90.6082 & -352.5872 \\
\hline Lig230 & -260.768 & -156.516 & -417.284 \\
\hline
\end{tabular}

Table 3. Lipinski's rule of five (RO5) to determine the pharmacological and biological activity of the top leading compounds.

\begin{tabular}{|c|c|c|c|c|c|}
\hline \multirow[b]{2}{*}{ Compound } & \multicolumn{5}{|l|}{ Drug-likeness* } \\
\hline & $500 \leq \mathrm{MW}$ & $10 \leq \mathrm{N}$ or $\mathrm{O}$ & $5 \leq \mathrm{NH}$ or $\mathrm{OH}$ & $4.15 \leq \mathrm{MLog} P$ & Violation \\
\hline Lig68 & $643.88 \mathrm{~g} / \mathrm{mol}$ & 11 & 4 & 3.66 & 2 \\
\hline Lig434 & $662.18 \mathrm{~g} / \mathrm{mol}$ & 13 & 2 & 2.87 & 2 \\
\hline Lig230 & $539.59 \mathrm{~g} / \mathrm{mol}$ & 11 & 2 & 2.45 & 2 \\
\hline
\end{tabular}

*Lipinski's rule states that, an orally active drug has no more than one violation.

\section{Figures}




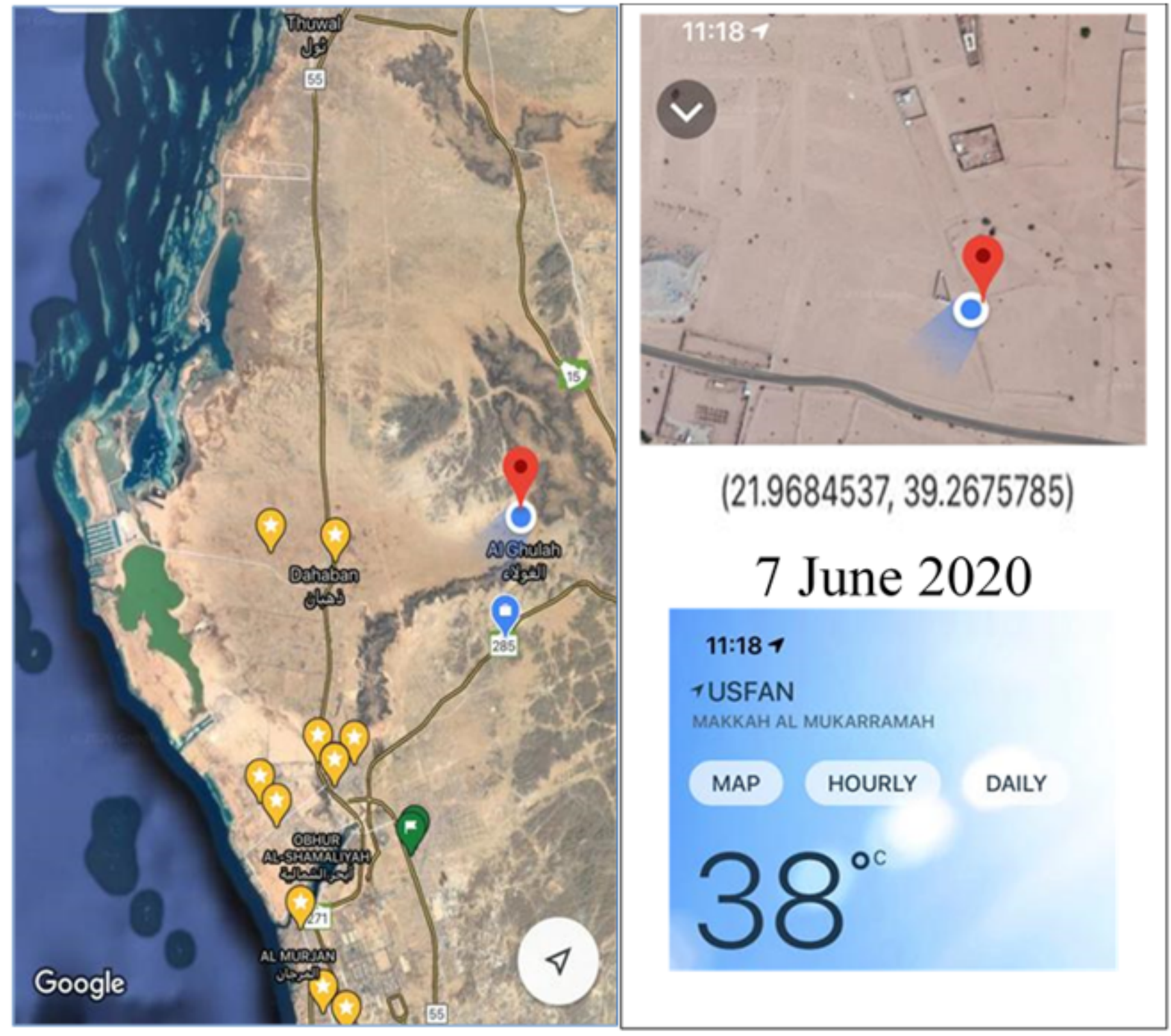

\section{Figure 1}

Site map of Al Gholah region near Asfan road $(21.9684537,39.2675785)$ - Jeddah province show-ing the locations of the collected samples of Rhazya Stricta plant. 


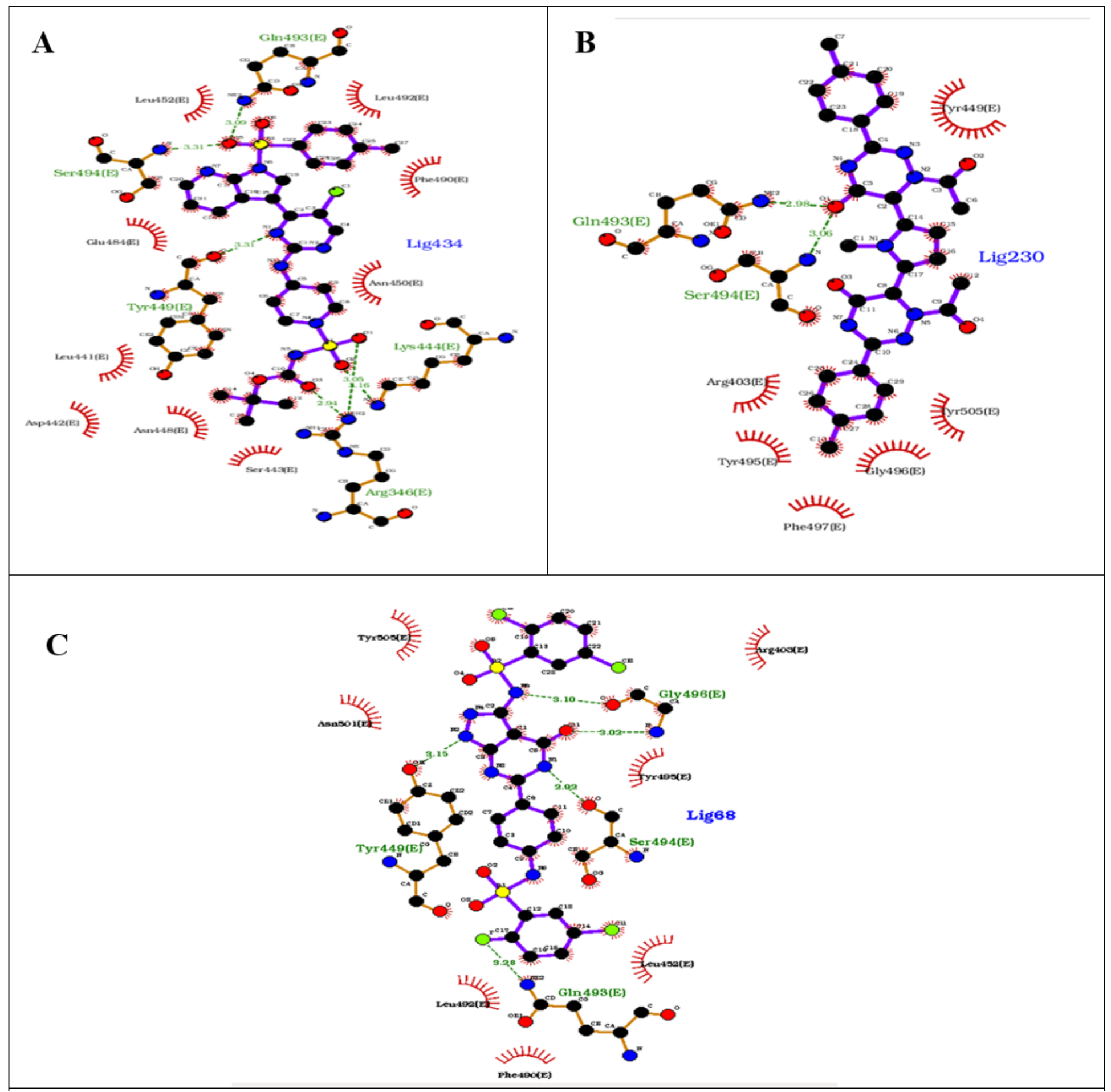

Figure 2

Docking interactions of (A) ligand 434, (B) ligand 230, and (C) Ligand 68 with the RBD of spike protein PDB I.D: 6M0J shows the hydrogen bonds and hydrophobic interactions with amino acid residues. 

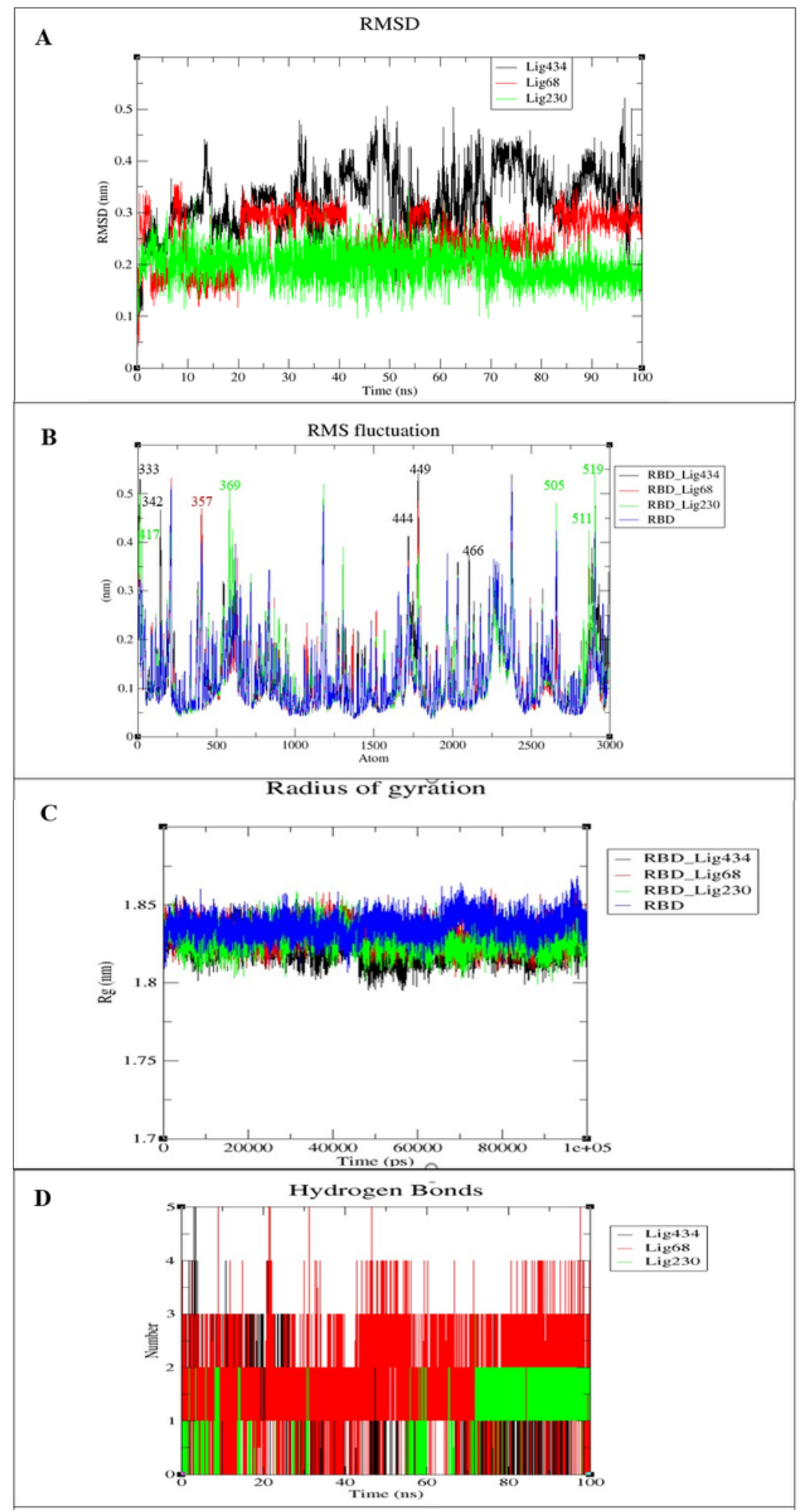

Figure 3

(A) Root mean square deviation (RMSD), (B) root mean square fluctuation (RMSF), (C) radius of gyration and (D) Hydrogen Bond interactions for all three complexes over the 100 ns simulation. 


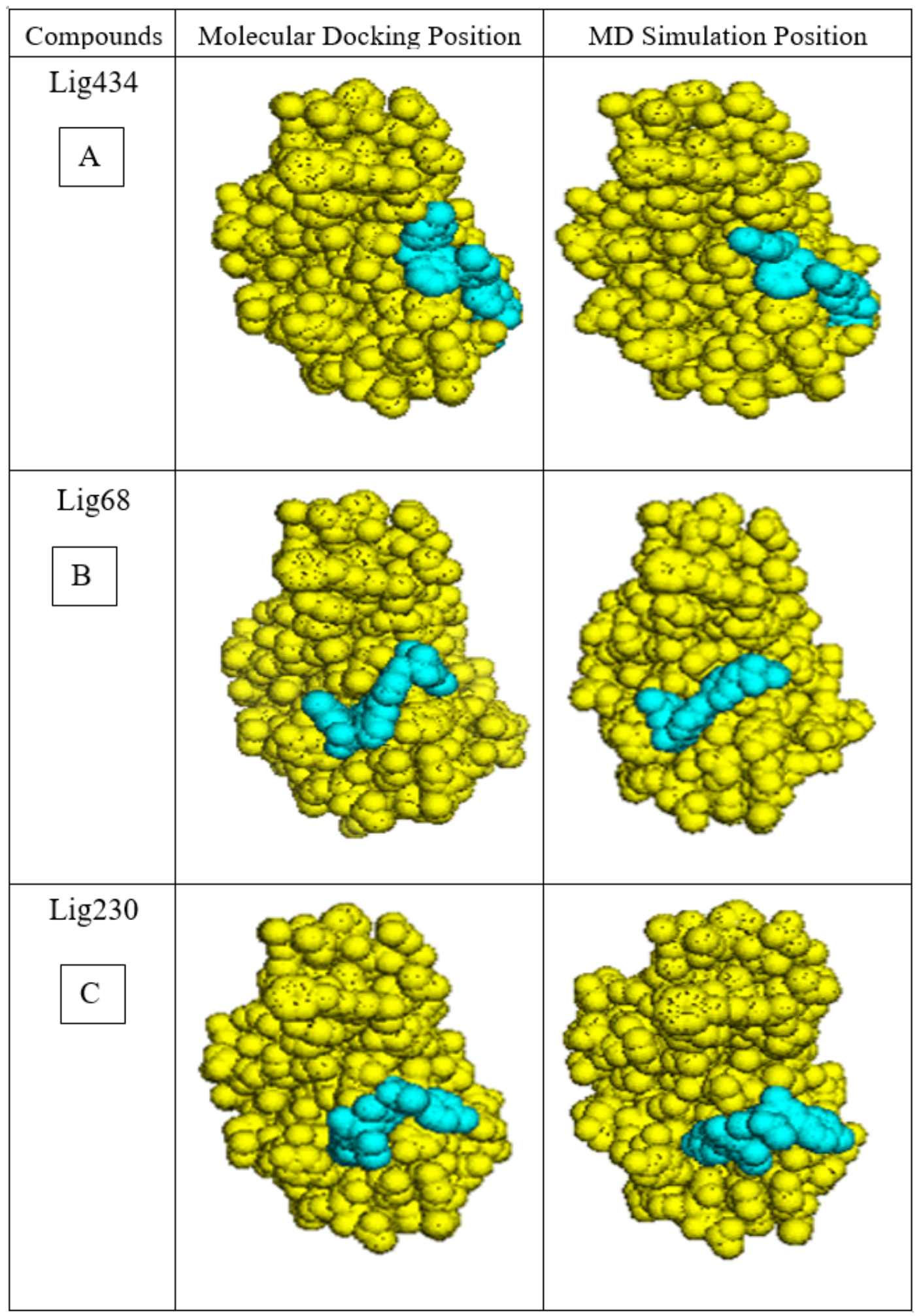

\section{Figure 4}

Binding pose of molecular docking and MD simulation of the leading non-alkaloid compounds and their position in the active site of RBD ID 6M0J. Surface view of (A) Lig 434, (B) Lig68, and (C) Lig230 in Cyan color and RBD in yellow color showing the transition of docked poses through $100 \mathrm{~ns}$ MD simulation. 


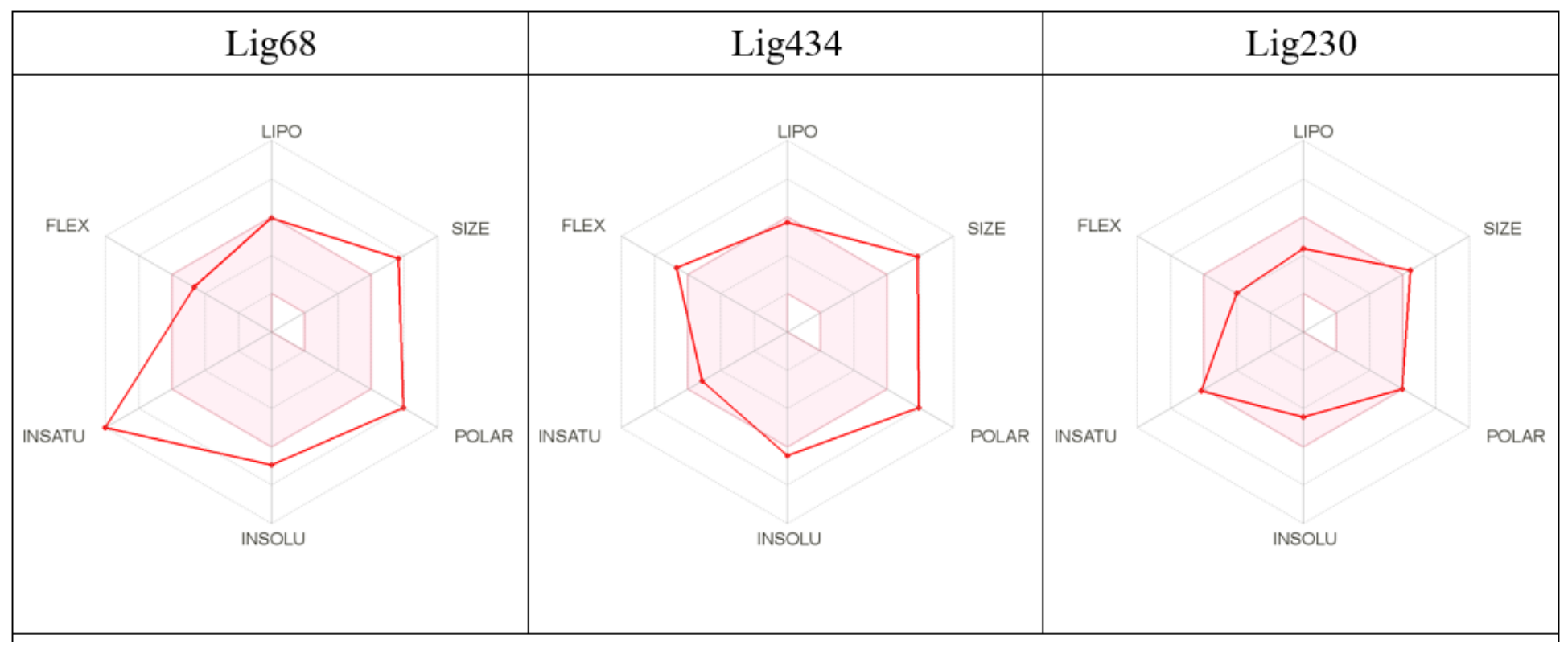

\section{Figure 5}

Radar-like representation of the drug-likeness of the leading compounds calculated by SwissADME. Lig 68, Lig 434, and Lig 230. LIPO: Lipophility (- $0.7<$ XLOGP3 < + 5.0), SIZE: $(150 \mathrm{~g} \backslash \mathrm{mol}<\mathrm{MW}<500 \mathrm{~g} \backslash \mathrm{mol})$ POLAR: Polarity $\left(20 \AA^{2}<\right.$ TPSA $\left.<130 \AA^{2}\right)$, INSOLU: Insolubility $(0<$ Log $S<6)$, INSAU: Insaturation $(0.25<$ Fraction Csp3 $<1)$, FLEX: Flexibility $(0<\mathrm{N}$. rotatable bonds $<9)$. 